\title{
Screening for Various Haemoglobinopathies to Observe Prevalence and Patterns in Population of District Datia (M.P.), India
}

Nalini Mishra ( $\square$ nalini007mishra@gmail.com )

Model Rural Health Research Unit, Datia, M.P. India

\section{S. Rajasubramaniam}

ICMR-National Institute for Research in Tribal Health

\section{S.L. Balakrishna}

Indira Gandhi National Tribal University

Archana Kumawat

Model Rural Health Research Unit, Datia, M.P. India

Rajesh Gaur

Govt. Medical College, Datia

\section{Amita Sharma}

Govt. Medical College, Datia

\section{Rajesh Gupta}

Govt. Medical College, Datia

\section{Aparup Das}

Govt. Medical College, Datia

\section{Research Article}

Keywords: thalassemia, G6PD, Sickle cell, haemoglobin, Datia region

Posted Date: January 25th, 2022

DOI: https://doi.org/10.21203/rs.3.rs-1245625/v1

License: (1) (1) This work is licensed under a Creative Commons Attribution 4.0 International License. Read Full License 


\section{Abstract}

Purpose: Haemoglobinopathies are the most common inherited disorder of Red Blood Cells across globe and one of the major public health problems in many regions of India. Variation in ethnic and regional prevalence is observed. The prevalence and pattern of haemoglobinopathies in Datia region has not been reported limiting the knowledge of diseases profile in this region. Present work showed the broad view of various haemoglobinopathies in the local area and population at risk. Efforts were made to identify prevalence of Sickle cell anaemia, $\beta$-thalassemia major and G-6-P-D deficiency among patients attending various OPDs of District Hospital, Datia, Madhya Pradesh, India.

Methods: All anaemia patients referred by Govt. hospitals/facilities (Datia District hospital) exhibiting anaemia were screened for various haemoglobinopathies. A total of 605 cases exhibiting anemia received from September 2017 to March 2020 at the Model Rural Health Research Unit (MRHRU), Datia, M.P. were tested for different haemoglobinopathies. Samples were received from District Hospital Datia. The samples were tested by solubility and cellulose acetate electrophoresis and HPLC and G6PD deficiency.

Results: A total 605 patients were screened for haemoglobinopathies from District Hospital, Datia. It was found that 13 cases $(2.14 \%)$ were of $\beta$ thalassemia trait and other rare variants followed by 4 cases $(0.66 \%)$ of sickle cell trait. A total of 3 cases $(0.5 \%)$ of $\beta$ thalassemia major was observed in total samples of 605 .

Conclusion: Very low prevalence rate of Sickle cell anaemia and thalassemia was observed. Large scale screening in the region is required for identifying the true burden.

\section{Introduction}

Haemoglobinopathies are considered the commonest genetic defect globally ${ }^{1}$. Datia is the district headquarters of Datia district (a sub-rural region), $69 \mathrm{~km}$ from Gwalior and is surrounded by state U.P., India on north side. The haemoglobinopathies are one of the most neglected disease ${ }^{2}$ espcially in rural settings. The health and medical facilities are mainly provided by the District medical hospital and disease profile is unknown here. The screening of haemoglobinopathies in Datia region has not been reported earlier. This study was aimed to screen the patients having severe anaemia from district hospital Datia for sickle cell disease, $\beta$-thalassemia major and G6PD deficiency. Further, this study was mandated to provide supportive care and management of sickle cell through counselling and prevent birth of future affected babies.

\section{Material \& Methods}

All anaemic patients ( $<11 \mathrm{gm} / \mathrm{dL}$ haemoglobin) and other suspected of haemolytic disorder referred by Govt. hospitals/facilities were referred to Model Rural Health Research Unit, Datia laboratory for diagnosis. The samples were obtained after taking written and understood consent (informed consent 
form) from patients and under the age of 18 years of pateints were taken from their parent/legal guardians. After obtaining the informed consent about $2 \mathrm{~mL}$ intravenous blood, each free from blood transfusion was collected in ethylene diaamine tetra acetic acid (EDTA) vials as anticoagulant. In total, 605 samples were screened for various haemoglobinopathies. Presence of sickle haemoglobin (HbS) was tested by solubility test ${ }^{3,4}$, confirmation of genotype was done by Cellulose acetate membrane electrophoresis ${ }^{3,7}$ at $\mathrm{pH}$ 8.6. Quantification of $\mathrm{HbA} 2$ and $\mathrm{HbF}$ was performed by CE-HPLC ${ }^{7}$. $\beta$ thalassemia was investigated by CE-HPLC. Parental analysis was done to confirm genotype. Screening for G6PD deficiency was performed by DPIP decolourization method ${ }^{8,9}$. The study was carried out in accordance with Helsinki declaration. This project was part of the service provided by MRHRU Datia. A post facto ethical clearance was taken to publish the collected data and also to elaborate this on-going project. Statistical analysis is done by using excel, the categorials analysis is presented as percentages. The datasets used and/or analysed during the current study available from the corresponding author on reasonable request.

\section{Results}

In total screened 605 patients, $485(80.2 \%)$ were females and $120(19.8 \%)$ were males. Age of majority of participants (49.3\%) was in the age group of $21-30$ years followed by the $0-10$ years group $(22.3 \%), 11$ 20 years group (19.0\%) and 31- above years group (9.4\%). Caste-wise distribution revealed that $48.6 \%$ patients were from Other Backward Classes (OBC), 31.4\% from Scheduled Caste (SC) communities followed by $14.9 \%$ general category, Scheduled Tribe (ST) constituted only $1.65 \%$ of the samples screened also $3.5 \%$ did not disclose their caste category. Six patients were Blood Tansfusion dependent. Four subjects showed the presence of $\mathrm{HbS}$ (HbAS) (Sickle Cell Carrier) and 13 subjects were $\beta$ thalassemia trait (Table 1) and three cases were observed of thalassemia major. No G6PD deficiency individuals were identified in total tested 605 samples (Table 1). The prevalence of $\beta$-thalassemia major and $\beta$-thalassemia minor were found to be $0.5 \%$ and $2.14 \%$ respectively (Table 1 ), also the prevalence of sickle cell trait found was $0.66 \%$. All $\beta$-thalassemia major were young children (Table 3 ), as were reported to hospital early due to difficulty they face in normal living. Analyses of $\beta$-thalassemia trait by age showed more adults in their 21-30 age group amd too majority being females (Table 2).

Table 1

Distribution of patients according to haemoglobinopathy found in current study:

\begin{tabular}{|ll|}
\hline No. of patients (out of 605) & Haemoglobinopathy \\
\hline 4 & Sickle cell trait \\
\hline 13 & $\beta$-thalassemia trait \\
\hline 3 & thalassemia major \\
\hline 0 & G6PD deficiency \\
\hline
\end{tabular}


Table 2

Analyses of $\beta$-thalassemia trait by age, gender,cast and category distribution.

\begin{tabular}{|lllll|}
\hline B-thalassemia trait & Age & Gender & Cast & Category \\
\hline 1. & $21-30$ years & Female & Jha & OBC \\
\hline 2. & $11-20$ years & Female & Rajput & OBC \\
\hline 3. & $21-30$ years & Female & Sharma & Gen \\
\hline 4. & $21-30$ years & Female & Tilwani & Gen \\
\hline 5. & $21-30$ years & Male & Prajapati & SC \\
\hline 6. & $21-30$ years & Female & Prajapati & SC \\
\hline 7. & 31 and Above & Male & Kukreja & Gen \\
\hline 8. & $21-30$ years & Female & Kukreja & Gen \\
\hline 9. & $0-10$ years & Male & Kukreja & Gen \\
\hline 10. & 31 and Above & Male & Sindhi & Gen \\
\hline 11. & 31 and Above & Female & Sindhi & Gen \\
\hline 12. & $21-30$ years & Female & Sindhi & Gen \\
\hline 13. & $21-30$ years & Female & Sindhi & Gen \\
\hline
\end{tabular}

Table 3

$\beta$-thalassemia major by age, gender, cast and category distribution:

\begin{tabular}{|lllll|}
\hline B-thalassemia major & Age & Gender & Cast & Category \\
\hline 1. & $0-10$ years & Male & Prajapati & SC \\
\hline 2. & $0-10$ years & Female & Kukreja & Gen \\
\hline 3. & $11-20$ years & Male & Sindhi & Gen \\
\hline
\end{tabular}

\section{Discussion}

The present study provides an overview on the presence of haemoglobinopathies in patients attending the district hospital, Datia. In the present study it was observed that the majority of the patients attending the clinic were females, mainly because of all suspected haemolytic anaemia/anaemia cases were referred by Gynaecology Department of District Hospital. The reason for the high proportion of the female patients may be due to commonly prevalent anaemia though the disease is not sex-linked ${ }^{10}$. Unlike sickle cell anaemia, $\beta$-thalassemia major is detected early among infants and as they require blood transfusion. Due to presence of tribes in Datia region it was expected that sickle cell disease could be prevalent, but 
results were contradictory ${ }^{11,12,13}$. The general prevalence of sickle cell anaemia and $\beta$-thalassemia trait lies between $1-44 \%$ and $3-17 \%$ respectively ${ }^{13}$. In this study a prevalence of $\beta$-thalassemia minor was found to be $2.14 \%$ and sickle cell trait $0.66 \%$ respectively in Datia District. The found cases have been provided by supportive care as after identification of such cases, the parents were adviced for screening of all members for haemoglobinopathies and antenatal screening in utero after conception. The $0 \%$ observance of G6PD deficiency might be due to the majority of the patients attending the clinic were females, mainly because of all suspected haemolytic anaemia/anaemia cases were referred by Gynaecology Department of District Hospital. As, G6PD deficiency is a genetic disorder and passed to the child from one or both parents. The $X$ chromosome carries the defect that causes this deficiency, from the two sex chromosomes. Since, males have only one $X$ chromosome, while females have two $X$ chromosomes $^{14}$. In males, one copy of the altered gene is enough to cause G6PD deficiency. However, in females, a mutation have to be present in both copies of the gene. Since it's less likely for females to have two altered copies of this gene, hence we are getting this kind of result in this study. Males are affected by G6PD deficiency much more frequently than females, and they are less reported to hospital. Limitations of the study are small sample size and it is hospital-based study. Community based studies are required for arriving at the true picture of the status of haemoglobinopathies in Datia District. Similarly, large scale studies are essential to identify G6PD deficiency among tribals and non-tribals to enable health authorities to carry out malaria control in the region ${ }^{14}$ as this region is reported to carry high incidence of Plasmodium vivax infection.

Approval by the appropriate ethics committee for research: The study was approved by the institutional ethics committee of ICMR- National Institute of Research in Tribal Health, Jabalpur, India via letter no. NIRTH/IE C/01/31/2021

\section{Declarations}

\section{Acknowledgements}

The manuscript has been approved by the Publication Screening Committee of ICMR-NIRTH, Jabalpur and assigned with the number ICMR-NIRTH/PSC/31/2021

\section{Funding:}

We would like to thank the Director of ICMR- NIRTH for providing all possible help to commence this project. We also thank Department of Health Research for their support in form of funding and other means.

I highly acknowledge the efforts of Dr. S. Rajasubramaniam in establishing the lab at Datia, training of Scientists and staff and support for confirmation of results by HPLC at ICMR-NIRTH, Jabalpur. He has given his full support as the Co investigator of the project. 
We also express our gratitude to Dean of the Datia Medical College for allowing us to take the samples from the patients and facilities to commence this piece of work. Last but not the least, we would to thank our lab Technicians, Mr. Rishi Badal and Mr. Saikant for performing the lab tests.

\section{References}

1. Suthat Fucharoen \& Pranee Winichagoon, Haemoglobinopathies in Southeast Asia. Indian J Med Res, October 2011, 134, pp 498-506.

2. David Weatherall, The inherited disorders of haemoglobin: an increasingly neglected global health burden, Indian J Med Res, October 2011, 134, pp 493-497.

3. Ronald J A Rent, Diagnosis of the Haemoglobinopathies, Clin Biochem Rev Vol, 2006.

4. Huntsman RG, Barclay GP, Canning DM, Yawson GI. A rapid whole blood solubility test to differentiate the sickle cell trait from sickle cell anaemia. J clin Pathol, 1970 dec; 23(9):781-3.

5. Pabis A, Sulis E, Alessio L, Mannucci PM. Cellogel electrophoresis of Haemoglobins. ClinicaChimica Acta 1968; 20(3); 449-453.

6. Dacie JV, Lewis SM, editors. Practical haematology. 7th ed. London: Churchill Livingstone, 1991.

7. Gwendolyn M. Clarke and Trefor N. Higgins, Laboratory Investigation of Hemoglobinopathies and Thalassemias: Review and Update, Clinical Chemistry, 2000, 46:8(B) 1284-1290.

8. Benstein RE. A rapid screening dye test for the detection of G6PD deficiency in red cells. Nature,1962, 194.

9. Pavri RS, Vasantha K, Baxi AJ. Usefulness of dicholoro-indophenol and fluorescent spot screening for G6PD deficiency. Acta Anthropogenetica, 1979, 3: 39.

10. Rajiv Yadav, Monica Lazarus, Pawan Ghanghoria, et al. Sickle cell disease in Madhya Pradesh, Central India: A comparison of clinical profile of sickle cell homozygote vs. sickle-beta thalassaemia individuals, Hematology, 2016, 21:9, 558-563, DOI: 10.1080/10245332.2016.1148893.

11. Kar BC, Satapathy RK, Kulozik AE, et al. Sickle cell disease in Orissa State, India. The Lancet, 1986, 328:1198-201.

12. Kar BC. Sickle cell disease in India. JAPI. 1991; 39 (12):954-60.

13. Teli AB, Deori R, and Saikia SP. Haemoglobinopathies and $\beta$-Thalassaemia among the Tribals Working in the Tea Gardens of Assam, India. J of Clin and Diag Res. 2016, 10(12): LC19-LC22. DOI: 10.7860/JCDR/2016/22010.9002.

14. Nicole LaRue, Maria Kahn, Marjorie Murray, et al., Comparison of Quantitative and Qualitative Tests for Glucose-6-Phosphate Dehydrogenase Deficiency, Am. J. Trop. Med. Hyg., 2014, 91(4), pp. 854861

\section{Supplementary Files}

This is a list of supplementary files associated with this preprint. Click to download. 
- analysisaccessexplainedSR.doc

- rawdatahaemoglobinopathiesdatia.xls 